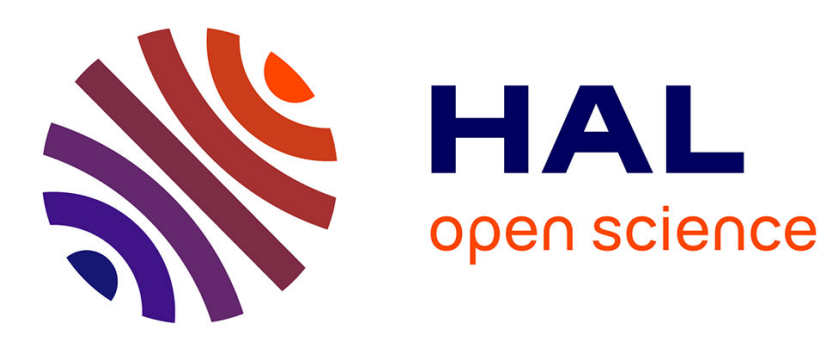

\title{
Monitoring of methotrexate chlorination in water.
}

B. Roig, B. Marquenet, I. Delpla, Vincent Bessonneau, Alain Sellier, C. Leder, Olivier Thomas, R. Bolek, K. Kummerer

\section{To cite this version:}

B. Roig, B. Marquenet, I. Delpla, Vincent Bessonneau, Alain Sellier, et al.. Monitoring of methotrexate chlorination in water.. Water Research, 2014, 57, pp.67-75. 10.1016/j.watres.2014.03.008 . hal01016617

\section{HAL Id: hal-01016617 https://hal-univ-rennes1.archives-ouvertes.fr/hal-01016617}

Submitted on 30 Jun 2014

HAL is a multi-disciplinary open access archive for the deposit and dissemination of scientific research documents, whether they are published or not. The documents may come from teaching and research institutions in France or abroad, or from public or private research centers.
L'archive ouverte pluridisciplinaire HAL, est destinée au dépôt et à la diffusion de documents scientifiques de niveau recherche, publiés ou non, émanant des établissements d'enseignement et de recherche français ou étrangers, des laboratoires publics ou privés. 


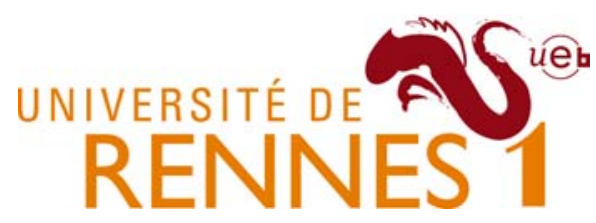

This is the author's final draft post-refeering (post-print)

Find more peer-reviewed articles on our open access repository:

http://hal-univ-rennes1.archives-ouvertes.fr/ 


\title{
Monitoring of methotrexate chlorination in water
}

\author{
B. Roig ${ }^{a, b, c, *}$, B. Marquenet ${ }^{c}$, I. Delpla ${ }^{c}$, V. Bessonneau ${ }^{c, d}$, A. Sellier ${ }^{b, c}$, \\ C. Leder ${ }^{e}$, O. Thomas ${ }^{b, c}$, R. Bolek ${ }^{e}$, K. Kummerer ${ }^{e}$
}

${ }^{a}$ Nîmes University, Rue du docteur George Salan, 30000 Nîmes, France

b INSERM U1085-IRSET, LERES, France

${ }^{c}$ EHESP Rennes, Sorbonne Paris Cité, Avenue du Professeur Léon Bernard, CS 74312, 35043 Rennes Cedex, France

dUniversity of Waterloo, Department of Chemistry, 200 University Ave., Waterloo, ON N2L 3G1, Canada

${ }^{\mathrm{e}}$ Institute for Sustainable and Environmental Chemistry, Leuphana Universität, Lüneburg, Germany

\begin{abstract}
A B S T R A C T
Anti-cancer drugs are an important class of pharmaceutical products. Methotrexate (MTX) is a folic acid antagonist used in high doses as antimetabolite in anti-cancer treatment as well as in low doses for the treatment of rheumatoid arthritis and adults' psoriasis. In the past, several anti-cancer drugs, including methotrexate, have been found in the environment. Their presence in water, especially if used for the production of drinking water, is even in low concentrations of particular interest, due to the risk to retrieve them in the consumed water and their high activity and grave effects. But prior to usage as drinking water, raw waters are treated and chlorination is a common practice in several countries. As such a treatment can lead to the formation of organochlorine in water, the study of the fate of MTX during chlorination in a batch trial was carried out. The reaction was monitored by dissolved organic carbon (DOC) and by fluorescence and UV spectroscopy. Investigation of by-products formed was done with liquid chromatography/mass spectrometry (LC/MS). Under the given experimental conditions, Methotrexate was eliminated rapidly ( $t_{1 / 2}$ around $21 \mathrm{~min}$ ). However, DOC elimination was incomplete. Monitoring with LC-MS showed the formation of a monochlorinated transformation product of MTX.

In silico analysis of the proposed transformation products for different carcinogenic, mutagenic and genotoxic endpoints with different software platforms provided no clear evidence that the possible transformation products after chlorination might be more toxic than the parent compound. However, since a number of alerts is altered after chlorination, it cannot be excluded that the toxicity of these transformation products might be modulated compared with the parent compound.
\end{abstract}

\section{Introduction}

In the last decade the presence of pharmaceuticals, ranging from nanograms to a few micrograms per liter, has been reported in the aquatic cycle including surface water, wastewater and groundwater (Besse and Garric, 2008; Buerge et al., 2006; Kasprzyk-Hordern et al., 2008; López-Serna et al., 2012; Osorio et al., 2012; Petrovic et al., 2012; Ratola et al., 2012; Roberts and Thomas, 2006; Verlicchi et al., 2012) and, to a

\footnotetext{
* Corresponding author. EHESP Rennes, Sorbonne Paris Cité, Avenue du Professeur Léon Bernard, CS 74312, 35043 Rennes Cedex, France. Tel.: +33466279571.

E-mail address: benoit.roig@unimes.fr (B. Roig).

http://dx.doi.org/10.1016/j.watres.2014.03.008
} 
lesser extent, drinking water (De Jongh et al., 2012; Mompelat et al., 2011; Wang et al., 2011a). Advances in analytical instruments have been a key factor driving their increased detection (Ferrer and Thurman, 2012; Grabic et al., 2012; Gros et al., 2012).

As for other micro-pollutants, their presence in environmental water, even at these very low concentrations, has raised particular interest. It points out the need to verify the efficacy of drinking water treatment processes for the removal of such compounds (Stackelberg et al., 2004; Westerhoff et al., 2005).

Drinking water treatment consists of several steps including filtration, flocculation, sedimentation and disinfection. Some treatment facilities also include ion exchange and adsorption onto activated carbon. Depending on the country, disinfection (chlorination, ozonation, UV radiation) is generally applied before the water enters the distribution system as drinking water to ensure elimination of potentially dangerous microbes (Gibs et al., 2007; Stackelberg et al., 2004). Ozonation and UV radiation are considered as powerful and effective disinfectant respectively. Contrary to ozonation and UV treatment whose remanence is very short, chlorination by treatment with chlorine, chlorine dioxide and sometimes chloramines is more often used because of its effectiveness in the treatment plant and its lasting presence and activity in the distribution network, although formation of harmful transformation products could be observed (Cantor et al., 1998; Hamidin et al., 2008; Meier et al., 1983).

Among various classes of pharmaceuticals, anti-cancer drugs are of particular environmental concern because they are potentially carcinogenic, mutagenic and genotoxic, even at low concentrations (Zounková et al., 2007) and reveal low biodegradability (Baumann and Preiss, 2001; Buerge et al., 2006; Straub, 2010). Methotrexate (MTX) is an analogous of folic acid and inhibits the enzyme Dihydrofolate reductase. It is used in chemotherapy at high doses and at low doses in the treatment of some autoimmune diseases like rheumatoid arthritis, adult psoriasis or ectopic pregnancy. With intravenous administration, $80-90 \%$ of the administered dose is excreted unchanged in the urine within $24 \mathrm{~h}$ (Drug Bank). It enters the environment via urban wastewaters (Castiglioni et al., 2006, 2005; Catastini et al., 2008), hospital wastewaters (Aherne et al., 1985; Yin et al., 2010) and can be detected even in drinking water (Aherne et al., 1985).

Though the effect of chlorination has been investigated for a number of pharmaceutical products in wastewater (Bedner and MacCrehan, 2006; Hey et al., 2012; Lee and von Gunten, 2010; Li and Zhang, 2012), surface water (Meyer et al., 2002; Shah et al., 2006; Wang et al., 2011b) and pure water (Li et al., 2011; Mash, 2010; Quintana et al., 2010; Rodil et al., 2012; Soufan et al., 2012), anti-cancer drugs in general and MTX in particular have received very low attention despite their high activity, possible promotion of cancer and teratogenic risk. The only anti-cancer drug yet investigated is cyclophosphamide (Besse et al., 2012; Huber et al., 2005; Kümmerer and Al-Ahmad, 2010; Mompelat et al., 2011).

Experimental toxicity testing of identified transformation products (TP) is often difficult, since many of them are not available commercially. Computer models calculating quantitative structure activity relationship (QSAR) are important tools to overcome this limitation. Once structure elucidation of any TP has been performed, these structures can be investigated using QSAR programs in order to predict the toxic potential of TPs for different toxicological endpoints and other environmental parameters. A set of programs for predicting biodegradation should be applied in order to take into account that the available programs might have individual strengths because of different algorithms and training sets.

The main aim of this study was to monitor the fate of MTX during chlorination (by using spectroscopic methods) with regard to the possible formation of transformation products (by LC/MS).

\section{Materials and methods}

\subsection{General methodology}

Chlorination was performed during $5 \mathrm{~h}$ at $21 \pm 3^{\circ} \mathrm{C}$ with initial $\mathrm{pH}$ of 8.6 (decreasing to $\mathrm{pH} 7.6$ during reaction due to hydrochloric acid production). Experiments were carried out in a $100 \mathrm{~mL}$ reactor. Working concentration of MTX was $1 \mathrm{mg} / \mathrm{L}$ in pure water. Chlorine was added as sodium hypochlorite to ensure a molar ratio $\mathrm{MTX}: \mathrm{Cl}_{2}$ of 1:100. The resulting mixture was stirred during 15-20 s to achieve a homogenous solution. DOC (NF EN 1484), residual chlorine, and $\mathrm{pH}$ were measured to follow the general progress of the chlorination. Samples were taken and measured by UV-spectrophotometry in order to simply follow the kinetics of MTX removal. The relative MTX concentration variation was assessed by fluorescence after photooxidation of the chlorinated sample. Finally, LC/MS was used for a preliminary monitoring of possibly formed transformation products.

\subsection{Material}

For basic measurements, $\mathrm{pH}$ was measured with an electrode (pHenomenal ${ }^{\circledR}$ pH 1000 L). A DPD comparator disk kit CIFEC was used for residual chlorine quantification. DOC was measured following chemical oxidation with sodium persulfate using a TOC-meter (OI Analytical 1010).

Qualitative assessment of MTX degradation was followed by UV-spectrophotometry (Lambda 35 Perkin Elmer) using a $100 \mathrm{~mm}$ quartz circulation cell connected with a closed loop circuit. Scan speed of wavelength range (200-400 nm with step width of $1 \mathrm{~nm}$ and a lamp change at $326 \mathrm{~nm}$ ) was fixed at $1920 \mathrm{~nm} / \mathrm{min}$. A spectrum was acquired every minute.

Fluorescence spectra were measured with a Xenius spectrofluorometer (Safas, Monaco) equipped with a $1 \mathrm{~cm}$ quartz cell. Fluorescence was measured at $462 \mathrm{~nm}$ with an excitation wavelength of $380 \mathrm{~nm}$. The photomultiplier (PM) voltage was generally set at $700 \mathrm{~V}$ and moved to 600 and $500 \mathrm{~V}$ according to the signal saturation.

Photooxidation followed by fluorescence measurement was used to assess the concentration of MTX during the chlorination. The photooxidation was performed by using the OXI50 device of Secomam (Alès, France) equipped with a low pressure mercury lamp emitting mainly at 185 and $254 \mathrm{~nm}$ and permitting direct photolysis of molecule. For this purpose 
the sample was introduced into a $0.5 \mathrm{~cm}$ quartz cuvette (volume $1 \mathrm{ml}$ ) and was irradiated $40 \mathrm{~s}$ before fluorimetry analysis.

Preliminary observation of transformation products was carried out by rapid resolution liquid chromatography coupled to mass spectrometry in tandem (LC/MS). The system consisted of Agilent LC 1200 Infinity LC equipped with an autosampler, column oven, and pumps. Separation was performed on a Zorbax Eclipse Plus C18 column $(100 \mathrm{~mm} \times 2.1 \mathrm{~mm} \times$ $1.8 \mu \mathrm{m}$, Agilent Technologies, Prague, Czech Republic), at $50^{\circ} \mathrm{C}$ (column oven). Its profile, at a flow rate of $0.4 \mathrm{~mL} / \mathrm{min}$ was in gradient mode and the mobile phases were water acidified with $0.01 \%$ formic acid (phase A) and acetonitrile (phase B). The initial composition of the mobile phase was $95 \%$ A (5\% B) maintained for $3 \mathrm{~min}$, then $70 \%$ A (30\% B) maintained for $6 \mathrm{~min}$, then $10 \%$ A (90\% B) maintained for $1 \mathrm{~min}$, then $90 \% \mathrm{~A}$ (10\% B) maintained for 3 min and finally the initial conditions for $2 \mathrm{~min}$.

The liquid chromatography was coupled with an electrospray ionization source to an Agilent 6460 Triple Quadrupole mass spectrometer equipped with electrospray jet stream technology operating in positive mode. The instrument was operated with the capillary voltage at $+4 \mathrm{kV}$, and nozzle voltage at $500 \mathrm{~V}$. Nitrogen was used as nebulizer gas of $45 \mathrm{psi}$, a drying gas of $5 \mathrm{l} / \mathrm{min}$ at $200^{\circ} \mathrm{C}$ and a sheath gas of $11 \mathrm{l} / \mathrm{min}$ at $250^{\circ} \mathrm{C}$. A full scan $(5,200 \mathrm{amu} / \mathrm{s})$ ranging from $\mathrm{m} / \mathrm{z} 50$ to 600 with a fragmentor voltage of $150 \mathrm{~V}$ was used for preliminary monitoring of transformation products.

\subsection{Chemicals and solvents}

Methotrexate was purchased from Sigma Aldrich (St Quentin Fallavier, France) and was in powder form with purity $>99 \%$. Three years of stability if stored at $-20^{\circ} \mathrm{C}$ was guaranteed by certificate. Acetonitrile (HPLC grade) was purchased from J.T Baker (Atlantic Labo ICS Bruges, France), formic acid (purity of 99\%) from Carlo Erba (Val de Reuil, France). Fenuron (CAS: 10142-8; purity $>99 \%$ ) was purchased from VWR (Fontenay sous Bois, France; certified quality, from Dr. Ehrenstorfer $\mathrm{GmbH}$, Augsburg, Germany). Sodium sulfite was bought from Merck. Pure water was produced using a Milli-Q water system (Millipore, Molsheim, France). Chlorine was supplied from $250 \mathrm{~mL}$ of concentrated sodium hypochlorite ( $9.6 \%$ of active chlorine) (Oxena, Portes les Valence, France). Stock solutions of MTX were prepared at a concentration of $50 \mathrm{mg} / \mathrm{L}$ in pure methanol and stored in darkness at $5{ }^{\circ} \mathrm{C}$. Individual working solutions were prepared freshly at the day of experiments at $1 \mathrm{mg} / \mathrm{L}$ in pure water by dilution of stock solutions. Chlorine solution was prepared at $1 \mathrm{~g} / \mathrm{L}$ (free chlorine) by diluting commercial sodium hypochlorite in pure water. The concentration of residual chlorine in this solution was verified everyday by sodium thiosulfate titration. After chlorination, reaction between chlorine and MTX was stopped with a molar excess of sodium sulfite $\left(\mathrm{Na}_{2} \mathrm{~S}_{2} \mathrm{O}_{3} / \mathrm{Cl}_{2}=3 / 1\right)$ before analysis.

\subsection{Analysis}

Fluorimetric quantification of MTX was based on works already described in the literature and dealing with the phototransformation (generally, in the presence of $\mathrm{H}_{2} \mathrm{O}_{2}$ ) of MTX which is originally weakly fluorescent, into the more fluorescent substance 2,4-diamino-pteridine-6-carboxylic acid (Lu and Juna, 1995; Salamoun et al., 1987; Uchiyama et al., 2012). In our study, due to the power of the UV lamp (irradiation band at $185 \mathrm{~nm}$ ) and the presence of chlorine, the phototransformation was performed without addition of $\mathrm{H}_{2} \mathrm{O}_{2}$ during $40 \mathrm{~s}$. Quantification of MTX was performed by fluorimetry after photooxidation. Confirmation of the measurement specificity was done for several times of chlorination with HPLC/MS (data not shown).

\subsection{In silico analysis of proposed transformation products}

MTX and its possible chlorination TPs were assessed by a set of in silico predictions for toxicity. This takes into account that the available programs might have individual strengths because of different algorithms and training sets. The set of available programs was Case Ultra V 1.4.5.1 (MultiCASE Inc.) (Saiakhov et al., 2013), the Oasis Catalogic software V.5.11.6 TB from Laboratory of Mathematical Chemistry, University Bourgas, Bulgaria and Leadscope software V. 3.0.11-1 with training sets from 2012 SAR Genetox Database provided by Leadscope (Roberts et al., 2000). Structure illustrations were performed by using MarvinSketch 5.8.0. Simplified molecular input line entry specification (SMILES) codes from the molecular TP structures were used for input of molecular structures.

Genotoxicity, mutagenicity and carcinogenicity were predicted with Case Ultra using the following QSAR models: Human Carcinogenicity (AOJ), Aneuploidy in Yeast (A6A), Micronucleus Formation in vivo composite (A7S),
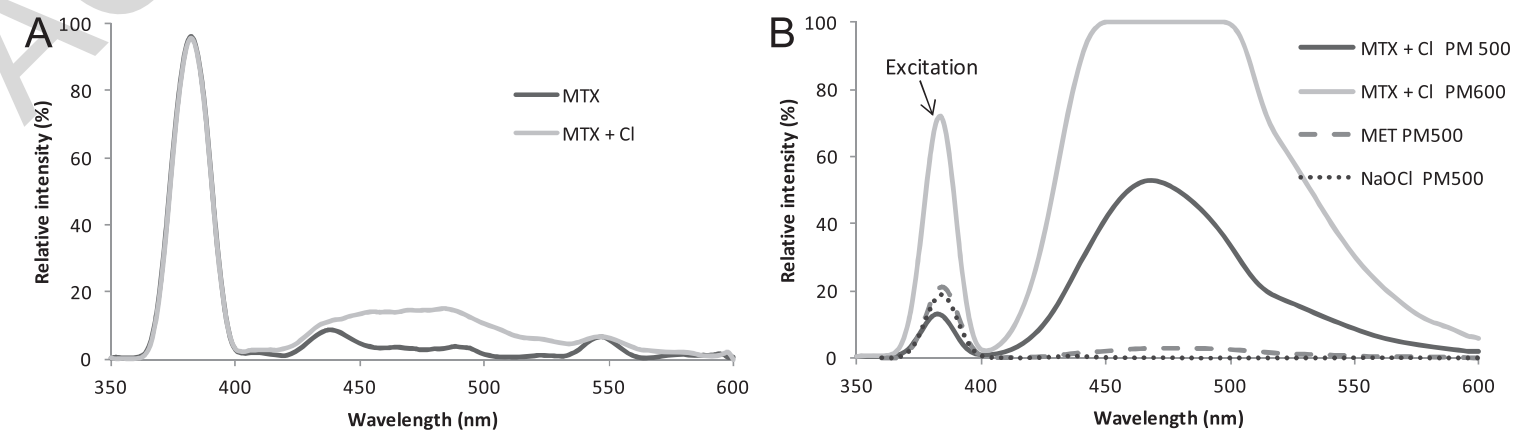

Fig. 1 - Fluorescence of MTX in the presence of chlorine. A: Before photochemical oxidation (PM 700V); B: After photochemical oxidation (PM 500 and 600V). 
Micronucleus Formation in vivo Mouse (A7T), Chromosomal Aberrations in vitro composite (A7U), Chromosomal Aberrations in vitro CHO cells (A7T), Rat Carcinogenicity (AOD), Mouse Lymphoma (ML), Mouse Carcinogenicity (AO8), Mutagenicity Ames (A2H) (Salmonella Ames mutagenicity updated from NTP, Genetox, FDA and others. It consists of the Salmonella typhimurium strains TA97, TA98, TA100, TA102, TA104, TA1535-TA1538 using a different training set compared with A7B), Unscheduled DNA Synthesis (UDS) Induction (A64). CASE Ultra predicts positive or negative structural alerts. Additional conclusions were "Out of Domain" - when an unknown structural fragment was found in the test chemical which excludes it from the chemical space of the training set of the applied model; "Inconclusive" (IN) - a significant portion of the test chemical is covered by unknown structural fragments, "Inconclusive" (IN(P)) - both positive and deactivating alerts were found in the same molecule.

Oasis Catalogic software predicted mutagenicity based on bacterial mutagenicity (module mutagenicity v.04) in $S$. typhimurium (Salmonella Catalogic model, SC).

Leadscope software predicted genotoxicity and mutagenicity using the following four QSAR modules: In vitro chromosome aberration composite (IVCA) Mammalian mutagenesis (MM), In vivo micronucleus (IVMN), bacterial mutagenesis (BM).

\section{Results and discussion}

\subsection{Monitoring of MTX}

In the presence of chlorine (during the chlorination), MTX natural fluorescence spectrum is modified (Fig. 1A) with the appearance of a broad peak between 420 and $520 \mathrm{~nm}$. Consequently MTX can't be measured directly in fluorescence. The photooxidation of the mixture MTX/Chlorine produces a strong increase of the fluorescence, with maximum absorption at $464 \mathrm{~nm}$ which was used for MTX quantification. Fig. 1B illustrates the necessity to modify the voltage of the photomultiplier (PM) to avoid signal saturation. The phototochemical reaction coupled with the adjustment of the

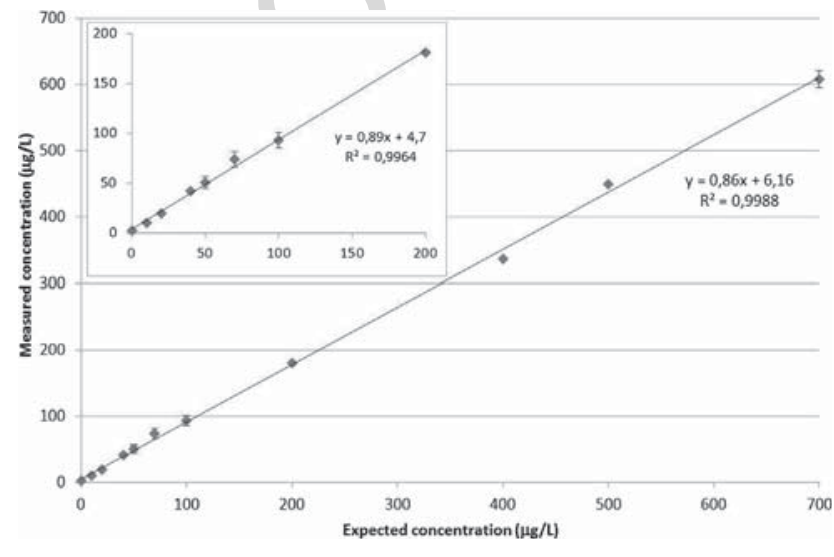

Fig. 2 - Comparison of MTX measurement by fluorimetry with regard to expected (known concentration prepared from standard solution) concentration $(n=2)$.

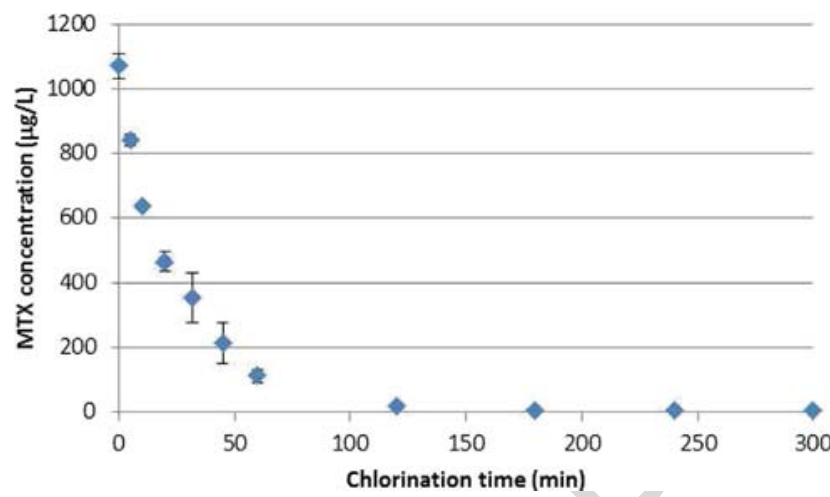

Fig. 3 - MTX concentration decrease during chlorination followed by fluorimetry monitoring $(n=2)$.

fluorescent signal allowed a better sensitivity of the method. Fig. $1 \mathrm{~B}$ also demonstrates the absence of interferences of photooxidation of $\mathrm{NaOCl}$ or MTX alone.

Fig. 2 shows that MTX concentration can be accurately determined by the method under these conditions. The calibration of MTX measurement was performed by comparison between expected (obtained from standard solutions) and measured (obtained after fluoro-photooxidation) concentrations. Measured concentrations were obtained from the response instrument (relative intensity) owing to a preliminary calibration curve obtained at PM 500, 600 and 700 (data not shown).

\subsection{Methotrexate chlorination}

Fig. 3 shows the decrease of the concentration of MTX during chlorination of a MTX solution of $1 \mathrm{mg} / \mathrm{L}$ in the presence of chlorine in a molar ratio of 1:100. The experiment was performed in duplicate.

Fig. 3 shows that a treatment of 120 min results in nearly complete elimination of MTX $(99.9 \% \pm 0.014 \%)$. During this time the reaction follows a kinetic of 1 st order $\left(\ln C_{0} / C=f(t)\right.$ is linear) and the half life of MTX under the conditions applied has been calculated as $20.6 \mathrm{~min}$.

Chlorination was monitored by UV spectroscopy. Fig. 4 shows the UV spectra of the solution of $1 \mathrm{mg} / \mathrm{L}$ MTX,

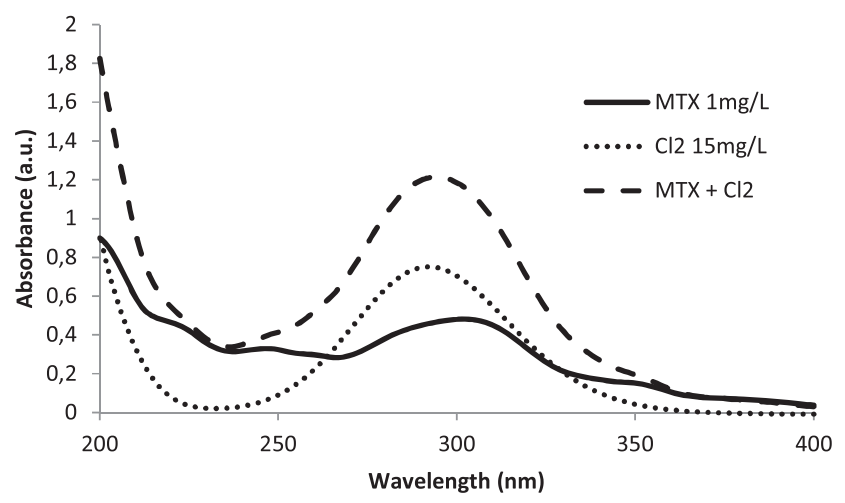

Fig. 4 - UV spectra of chorine, MTX and mixture (1 min contact time). 

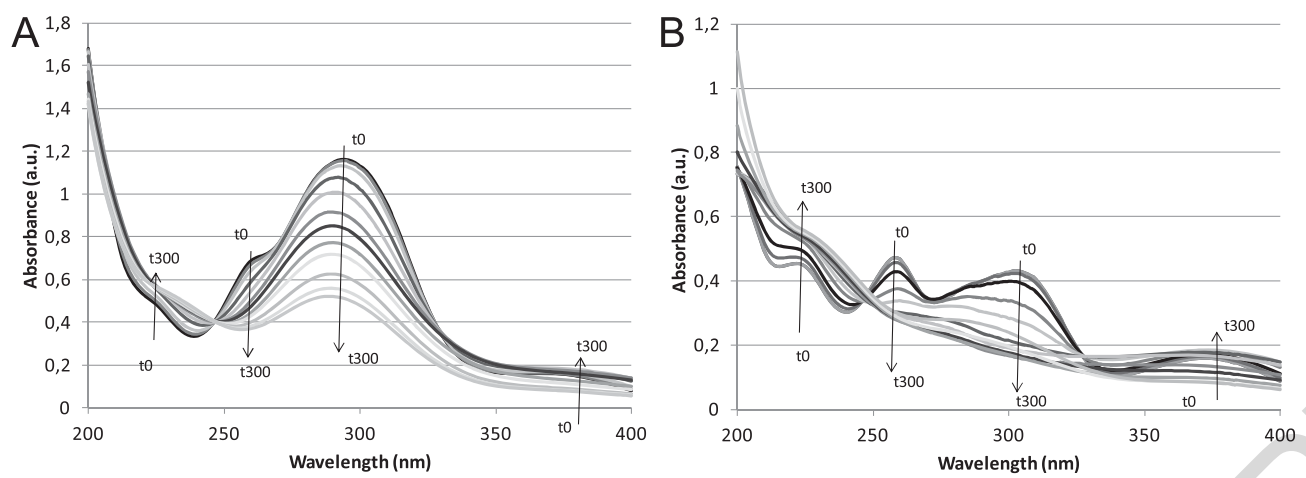

Fig. 5 - UV monitoring of MTX chlorination. A: Raw UV spectra; B: modified UV spectra (chlorine contribution subtracted).

$15 \mathrm{mg} / \mathrm{L}$ chlorine and of the mixture, whose spectrum is a combination of the spectra of chlorine and MTX solutions alone, respectively, with an absorption maximum at $292 \mathrm{~nm}$. Moreover, methotrexate showed characteristic peaks and shoulders at 222, 251, $302\left(\lambda_{\max }\right)$ and $353 \mathrm{~nm}$.

Under the operational conditions of chlorination, DOC determined at the beginning of the chlorination and for midreaction time, showed no significant decrease of its $0.5 \mathrm{mg} / \mathrm{L}$ initial concentration. Chlorine concentration decreased slowly during treatment period, between 15 and $20 \%$ and $\mathrm{pH}$ dropped one unit from 8.6 to 7.6 .
The set of UV spectra acquired during chlorination is characterized by a strong decrease of the absorbance at 292 and $263 \mathrm{~nm}$ and a slight increase of the absorbance at 220 and $360 \mathrm{~nm}$ (Fig. 5A). The presence of an isosbestic point at $247 \mathrm{~nm}$ reveals that the chlorination of MTX is a simple reaction between two absorbing compounds or mixtures of compounds (Pouet et al., 2004) characterized by a qualitative and quantitative conservation, i.e. with a fixed linear relationship between reagent(s) and product(s). In Fig. 5A, the reaction of MTX chlorination is characterized by the decreasing intensity of the spectrum of the mixture MTX/chlorine and the

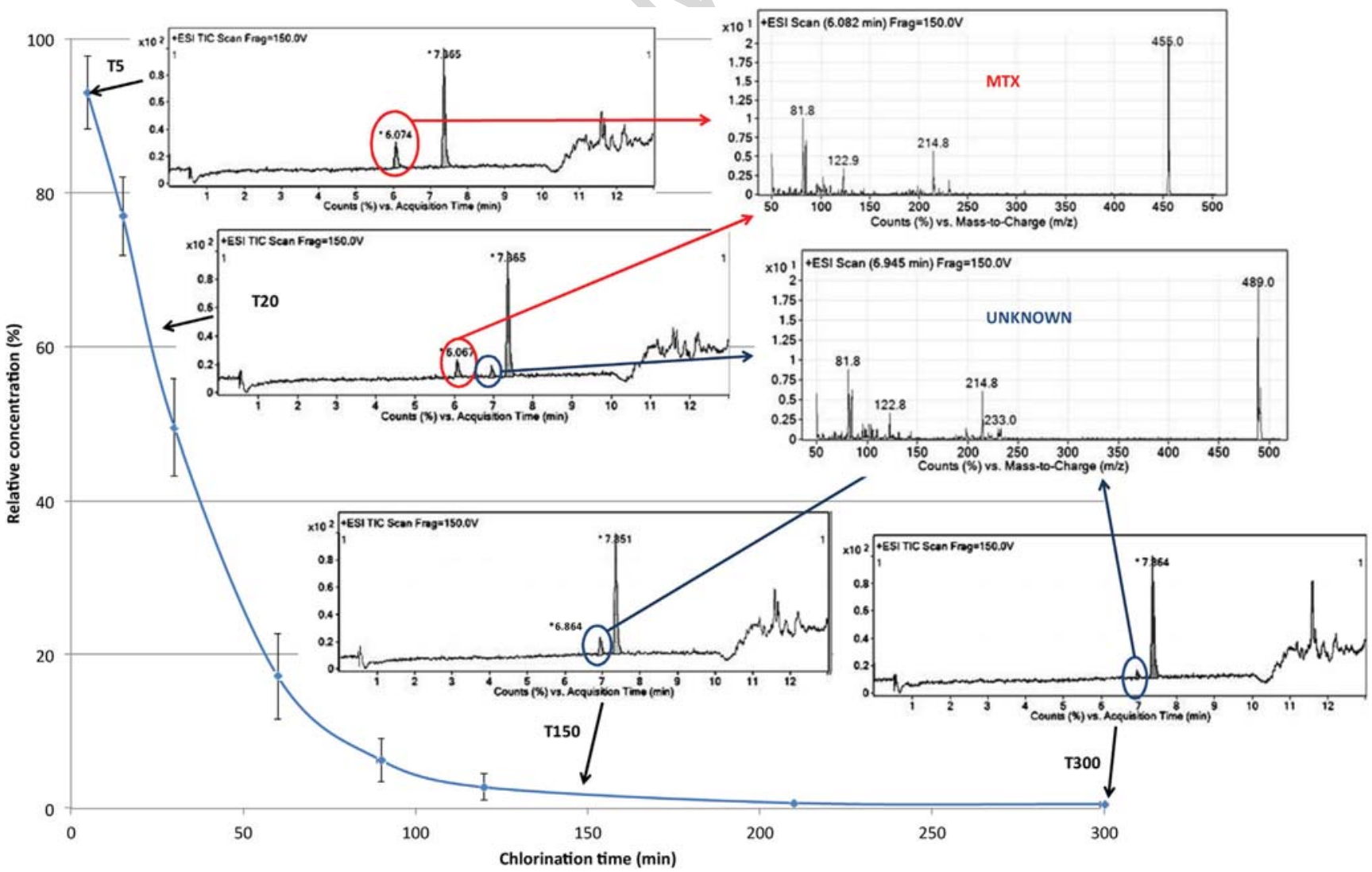

Fig. 6 - Behavior of MTX during chlorination in mass spectroscopy. Relative concentration corresponds to the ratio $C_{0} / C$ (obtained by fluorimetry after photooxidation); chromatograph peak at $7.4 \mathrm{~min}$ correspond to internal standard ( $n=2$ ). 
appearance of the spectrum of the residual chlorine and the transformation product of MTX.

This evolution is related not only to the transformation of MTX but also to chlorine reduction. Consequently, according to the additively property of UV absorption spectra, the subtraction of the decrease due to chlorine reaction to form the spectra of the mixture allows a better visualization of the MTX transformation (Fig. 5B). It is characterized by a rapid evolution of absorbance value at $302 \mathrm{~nm}$ during the first $50 \mathrm{~min}$. Such evolution is in close agreement with the results of the kinetic study of MTX elimination carried out by fluorimetry (Fig. 3). $50 \mathrm{~min}$ is about 2.5 half-life time and therefore at this moment only $20 \%$ of the initial MTX is present. Moreover, the new peak observed at $263 \mathrm{~nm}$ at the beginning of the reaction disappeared within the first $40 \mathrm{~min}$. Contrary to the other peaks and shoulders, absorbance peaks at 220 and $360 \mathrm{~nm}$ of MTX spectrum appear to increase with time until 150 min and then stabilize. The presence of the isosbestic point already mentioned shows that there is a quantitative relationship between the MTX and its transformation product (Pouet et al., 2004).

\subsection{Preliminary identification of transformation products}

Considering the removal kinetics and the evolution of UV spectra (showing shoulder or peak characteristic during the chlorination), specific chlorination times $(5,20,150$ and

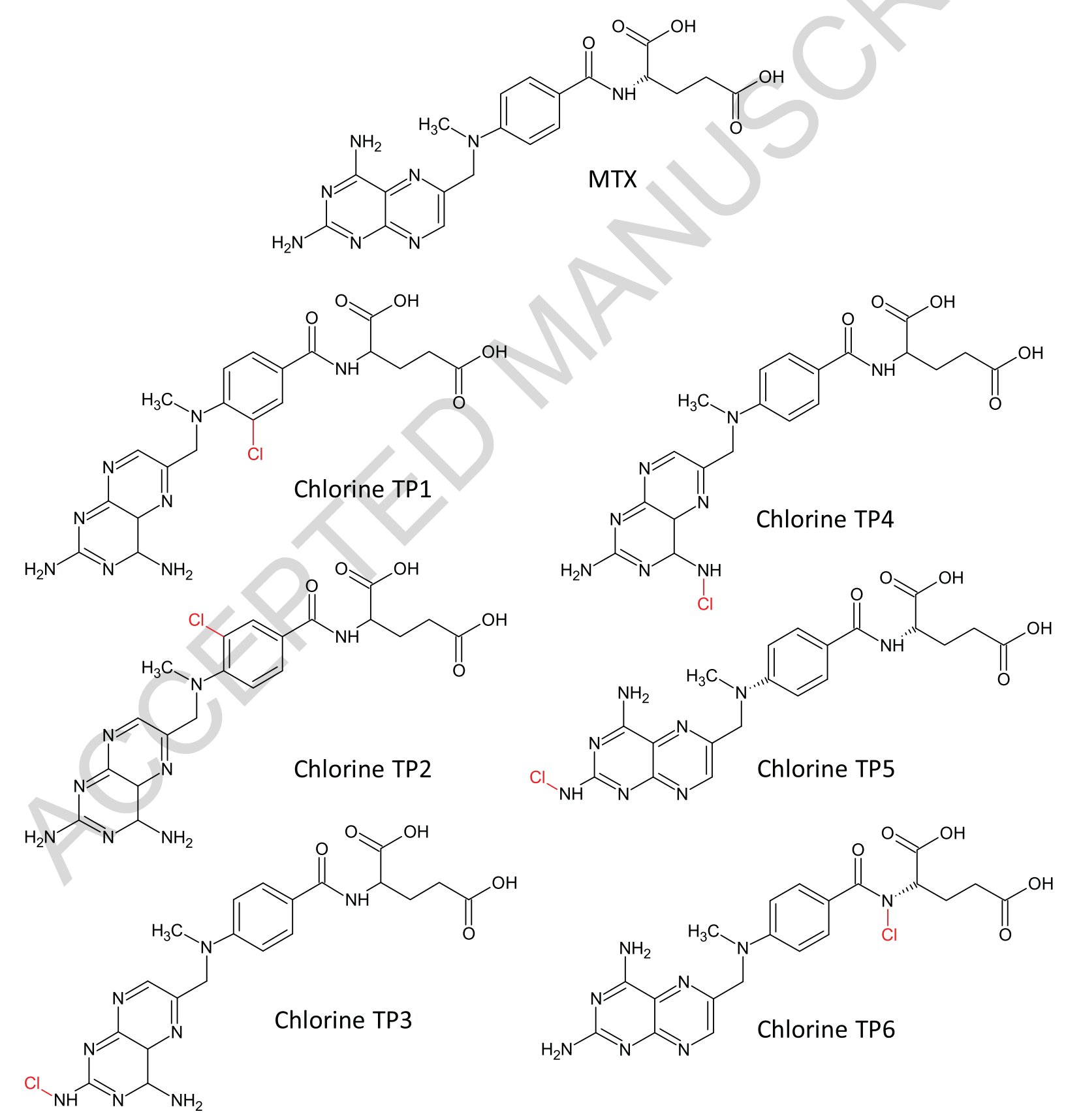

Fig. 7 - Proposed structures of the observed monochlorinated transformation product and the parent compound MTX. 
Table 1 - In silico predicted toxicity of MTX and its TPs.

\begin{tabular}{lcccccccccccccc}
\multicolumn{110}{c}{} & \multicolumn{10}{c}{ QSAR carcinogenicity, genotoxicity and mutagenicity } \\
\cline { 2 - 13 } & AOJ & A6A & A7S & A7T & A7U & A7V & A0D & ML & A08 & A64 & IVCA & MM & IVMN \\
\hline MTX & - & IN & + & + & IN(P) & - & - & + & + & IN(P) & + & - & + \\
Chlorine TP1 & IN(P) & IN & + & + & IN(P) & - & - & IN(P) & OD & IN(P) & + & - & + \\
Chlorine TP2 & IN(P) & IN & + & + & IN(P) & - & - & IN(P) & OD & IN(P) & + & - & + \\
Chlorine TP3 & IN(P) & IN & + & + & IN(P) & - & IN(P) & IN(P) & IN & IN(P) & + & - & + \\
Chlorine TP4 & IN(P) & IN & + & + & IN(P) & - & IN(P) & IN(P) & IN & IN(P) & + & - & + \\
Chlorine TP5 & IN(P) & IN & + & + & IN(P) & - & IN(P) & IN(P) & IN & IN(P) & + & - & + \\
Chlorine TP6 & OD & IN & + & IN(P) & + & - & IN(P) & IN(P) & IN & IN & + & + & + \\
\hline
\end{tabular}

Calculation has been made with the following QSAR modules: Human Carcinogenicity (A0J), Aneuploidy in Yeast (A6A), Micronucleus Formation in vivo composite (A7S), Micronucleus Formation in vivo Mouse (A7T), Chromosome Aberrations in vitro composite (A7U), Chromosome Aberrations in vitro CHO cells (A7V), Rat Carcinogenicity (A0D), Mouse Lymphoma (ML), Mouse Carcinogenicity (A08), UDS Induction (A64), In vitro chromosome aberration (IVCA), Mammalian mutagenesis (MM) and In vivo micronucleus (IVMN).

Positive (+), negative (-), inconclusive (IN), inconclusive with positive alert (IN(P)), out of domain (OD).

$300 \mathrm{~min})$ were selected for the pre-identification of the transformation products (TPs). According to spectra variation at $263 \mathrm{~nm}$ (Fig. 5A and B), two contact times (5 and $20 \mathrm{~min}$ ) were chosen for the identification of the by-product produced during the 40 first minutes of chlorination. A 150 min contact time was chosen in order to identify a potential stable byproduct characterized by the stabilization of absorbance peaks at 220 and $360 \mathrm{~nm}$. Finally, a contact time of $300 \mathrm{~min}$ was used to identify the compounds present in the mixture at the end of the reaction. Primary elimination of MTX was confirmed by LC/MS and only one stable TP seems to be present at least until 150 min of chlorination, with a mass spectrum corresponding to a chlorinated compound (Fig. 6). Afterward, the peak intensity of this TP was decreasing.

MTX mass spectra gives a hydrogen adduct as highest peak ( $\mathrm{m} / \mathrm{z}$ 455). Smaller fragments with $\mathrm{m} / \mathrm{z} 233,214$ etc could be observed. The transformation product's highest intensity mass peak was $\mathrm{m} / \mathrm{z}$ 489. The retention time was higher, indicating a decrease in polarity.

A first assumption could be that the unknown transformation product could be the monochloro-MTX as the MS signals differ only by a shift between 455 and 489 of the higher $\mathrm{m} / \mathrm{z}$ peak the difference of 34 being likely related to either the substitution of one hydrogen of the two amine functions by one chlorine atom or the chlorination of the aromatic ring in ortho position of the amine substituted position. This outcome needs to be confirmed with further experiments and analysis.

Table 2 - Positive alerts of MTX and its TPs predicted by the case ultra modules for micronucleus formation A7S and A7T.

\begin{tabular}{lrr} 
Compounds & \multicolumn{2}{c}{ Positive alerts } \\
\cline { 2 - 3 } & \multicolumn{1}{c}{ A7S } & \multicolumn{1}{c}{ A7T } \\
\hline MTX & $7,92,176,184$ & 24,100 \\
Chlorine TP 1 & $92,176,184$ & 100 \\
Chlorine TP 2 & $92,176,184$ & 100 \\
Chlorine TP 3 & $7,92,176$ & 24,100 \\
Chlorine TP 4 & $7,92,184$ & 24,100 \\
Chlorine TP 5 & $7,92,176$ & 24,100 \\
Chlorine TP 6 & 184 & 24,100 \\
\hline
\end{tabular}

Furthermore considering the experimental molar ratio of 1:100 for MTX/chlorine, on the one hand, and the chlorine dose of few $\mathrm{mg} / \mathrm{L}$ in drinking water treatment (for a residual concentration of chlorine of $0.2 \mathrm{mg} / \mathrm{L}$ for example), on the other hand, it can be expected that MTX traces found at the level of $\mathrm{ng} / \mathrm{L}$ in tap water could be eliminated under actual conditions, given a contact time of $1 \mathrm{~h}$ at least. However this would result in the formation of transformation products as found in this study. They have to be better characterized (in particular in term of related toxicity) for a sound risk assessment.

\subsection{In silico analysis of proposed transformation products}

The results of the applied QSAR modules were expressed in different ways depending on the software: For Case Ultra software, the predicted activities of the test chemicals are expressed as positive, inconclusive (IN(P)) (because both positive and deactivating alerts were found in the same molecule), inconclusive (IN) (because a significant portion of the test chemical is covered by unknown structural fragments), negative and out of domain (because unknown structural fragments were found which exclude the tested molecule from the chemical space of the training set of the applied model). For Oasis Catalogic software in the Salmonella Catalogic module, the results are expressed as mutagenic or not mutagenic. For Leadscope software, the predicted activity of the test chemicals is expressed as positive, negative and not in domain.

The possible structures of the monochlorinated transformation products together with the parent compound (Fig. 7) were applied in a set of QSAR models in order to predict the activity for different carcinogenic, mutagenic and genotoxic endpoints (table 1).

The QSAR analysis provided no clear evidence that the six chlorination TPs might be increased genotoxic or mutagenic compared with the parent compound. Particularly, predicted negativity for bacterial mutagenicity based on the Ames test was confirmed using three different QSAR platforms: A2H (Case Ultra, Multicase), SC (Mutagenicity module from Oasis Catalogic), BM (Bacterial mutagenicity from Leadscope). 
Since the alert combinations for micronucleus activity were altered in four different chlorination isomers, it cannot be excluded that the micronucleus activity might be modulated after chlorination (table 2). Of note is that five chlorination TPs had a positive alert for human carcinogenicity compared with a negative rating of the parent compound, although the resulting conclusion of the software was inconclusive due to the simultaneous detection of a negative alert.

\section{Conclusion}

This research demonstrates that a simple experimental methodology, using basic spectroscopic methods (UV and fluorimetry) can be useful to monitor the chlorination process of a methotrexate solution in water. Both chlorine consumption and MTX transformation can easily be followed during the reaction. A simple kinetic can be proposed with a half life of $20.6 \mathrm{~min}$ for a molar ratio of 1:100 MTX:chlorine. This finding is relevant with regard to the residence time of water and the residual chlorine concentration in distribution network. The monochloro-MTX is likely to be one of the main stable transformation product formed during chlorination. Further experiments with the help of high resolution LC/ MS-MS analysis are required to confirm this result and state on other potential transformation products. The toxicological properties of this transformation product should be assessed.

\section{Acknowledgments}

This research was financially supported by the European Union (European Commission, FP7 project PHARMAS, contract no. 265346). The authors wish to thank MultiCASE Inc. and Leadscope Inc. for providing CASE Ultra software and Leadscope software and LERES Extratox team for their analytical support.

\section{R E F E R E N C E S}

Aherne, G., English, J., Marks, V., 1985. The role of immunoassay in the analysis of microcontaminants in water samples. Ecotoxicol. Environ. Saf. 9, 79-83.

Baumann, F., Preiss, R., 2001. Cyclophosphamide and related anticancer drugs. J. Chromatogr. B. Biomed. Sci. Appl. 764, 173-192.

Bedner, M., MacCrehan, W.A., 2006. Transformation of acetaminophen by chlorination produces the toxicants 1,4benzoquinone and $\mathrm{N}$-acetyl-p-benzoquinone imine. Environ. Sci. Technol. 40, 516-522.

Besse, J.-P., Garric, J., 2008. Human pharmaceuticals in surface waters. Implementation of a prioritization methodology and application to the French situation. Toxicol. Lett. 176, 104-123.

Besse, J.-P., Latour, J.-F., Garric, J., 2012. Anticancer drugs in surface waters: what can we say about the occurrence and environmental significance of cytotoxic, cytostatic and endocrine therapy drugs? Environ. Int. 39, 73-86.

Buerge, I., Buser, H., Poiger, T., Müller, M., 2006. Occurrence and fate of the cytostatic drugs cyclophosphamide and ifosfamide in wastewater and surface waters. Environ. Sci. Technol. 40, $7242-7250$

Cantor, K., Lynch, C., Hildesheim, M., Dosemeci, M., Lubin, J., Alavanja, M., Craun, G., 1998. Drinking water source and chlorination byproducts. I. Risk of bladder cancer. Epidemiology 9, 21-28.

Castiglioni, S., Bagnati, R., Calamari, D., Fanelli, R., Zuccato, E., 2005. A multiresidue analytical method using solid-phase extraction and high-pressure liquid chromatography tandem mass spectrometry to measure pharmaceuticals of different therapeutic classes in urban wastewaters. J. Chromatogr. A 1092, 206-215.

Castiglioni, S., Bagnati, R., Fanelli, R., Pomati, F., Calamari, D., Zuccato, E., 2006. Removal of pharmaceuticals in sewage treatment plants in Italy. Environ. Sci. Technol. 40, 357-363.

Catastini, C., Mullot, J.-U., Boukari, S., Mazellier, P., Levi, Y., Cervantes, P., Ormsby, J.-N., 2008. Assessment of antineoplastic drugs in effluents of two hospitals. J. Eur. Hydrol. 39, 171-180.

De Jongh, C.M., Kooij, P.J.F., de Voogt, P., ter Laak, T.L., 2012. Screening and human health risk assessment of pharmaceuticals and their transformation products in Dutch surface waters and drinking water. Sci. Total Environ. 427-428, 70-77.

Drug Bank, http://redpoll.pharmacy.ualberta.ca/drugbank.

Ferrer, I., Thurman, E.M., 2012. Analysis of 100 pharmaceuticals and their degradates in water samples by liquid chromatography/quadrupole time-of-flight mass spectrometry. J. Chromatogr. A 1259, 148-157.

Gibs, J., Stackelberg, P.E., Furlong, E.T., Meyer, M., Zaugg, S.D., Lippincott, R.L., 2007. Persistence of pharmaceuticals and other organic compounds in chlorinated drinking water as a function of time. Sci. Total Environ. 373, 240-249.

Grabic, R., Fick, J., Lindberg, R.H., Fedorova, G., Tysklind, M., 2012. Multi-residue method for trace level determination of pharmaceuticals in environmental samples using liquid chromatography coupled to triple quadrupole mass spectrometry. Talanta 100, 183-195.

Gros, M., Rodríguez-Mozaz, S., Barceló, D., 2012. Fast and comprehensive multi-residue analysis of a broad range of human and veterinary pharmaceuticals and some of their metabolites in surface and treated waters by ultra-highperformance liquid chromatography coupled to quadrupolelinear ion trap tandem. J. Chromatogr. A 1248, 104-121.

Hamidin, N., Yu, Q.J., Connell, D.W., 2008. Human health risk assessment of chlorinated disinfection by-products in drinking water using a probabilistic approach. Water Res. 42, 3263-3274.

Hey, G., Grabic, R., Ledin, A., la Cour Jansen, J., Andersen, H.R., 2012. Oxidation of pharmaceuticals by chlorine dioxide in biologically treated wastewater. Chem. Eng. J. 185-186, 236-242.

Huber, M.M., Korhonen, S., Ternes, T.A., von Gunten, U., 2005. Oxidation of pharmaceuticals during water treatment with chlorine dioxide. Water Res. 39, 3607-3617.

Kasprzyk-Hordern, B., Dinsdale, R.M., Guwy, A.J., 2008. The occurrence of pharmaceuticals, personal care products, endocrine disruptors and illicit drugs in surface water in South Wales, UK. Water Res. 42, 3498-3518.

Kümmerer, K., Al-Ahmad, A., 2010. Estimation of the cancer risk to humans resulting from the presence of cyclophosphamide and ifosfamide in surface water. Environ. Sci. Pollut. Res. 17, 486-496.

Lee, Y., von Gunten, U., 2010. Oxidative transformation of micropollutants during municipal wastewater treatment: comparison of kinetic aspects of selective (chlorine, chlorine dioxide, ferrate VI, and ozone) and non-selective oxidants (hydroxyl radical). Water Res. 44, 555-566. 
Li, B., Zhang, T., 2012. pH significantly affects removal of trace antibiotics in chlorination of municipal wastewater. Water Res. 46, 3703-3713.

Li, Z., Fenet, H., Gomez, E., Chiron, S., 2011. Transformation of the antiepileptic drug oxcarbazepine upon different water disinfection processes. Water Res. 45, 1587-1596.

López-Serna, R., Petrović, M., Barceló, D., 2012. Occurrence and distribution of multi-class pharmaceuticals and their active metabolites and transformation products in the Ebro River basin (NE Spain). Sci. Total Environ. 440, 280-289.

Lu, G., Juna, H., 1995. Determination of trace methotrexate and 7$\mathrm{OH}$-methotrexate in plasma by high-performance liquid chromatography with fluorimetric detection. J. Liq. Chromatogr. 18, 155-171.

Mash, H., 2010. Assessing the fate and transformation by-product potential of trenbolone during chlorination. Chemosphere 81, 946-953.

Meier, J.R., Lingg, R.D., Bull, R.J., 1983. Formation of mutagens following chlorination of humic acid A model for mutagen formation during drinking water treatment. Mutat. Res. Toxicol. 118, 25-41.

Meyer, M., Adams, C., Wang, Y., Loftin, K., 2002. Removal of antibiotics from surface and distilled water in conventional water treatment processes. J. Environ. Eng. 128, 253-260.

Mompelat, S., Thomas, O., Le Bot, B., 2011. Contamination levels of human pharmaceutical compounds in French surface and drinking water. J. Environ. Monit. 13, 2929-2939.

Osorio, V., Marcé, R., Pérez, S., Ginebreda, A., Cortina, J.L., Barceló, D., 2012. Occurrence and modeling of pharmaceuticals on a sewage-impacted Mediterranean river and their dynamics under different hydrological conditions. Sci. Total Environ. 440, 3-13.

Petrovic, M., Barcelò, D., Al Aukidy, M., Verlicchi, P., Jelic, A., 2012. Monitoring release of pharmaceutical compounds: occurrence and environmental risk assessment of two WWTP effluents and their receiving bodies in the Po Valley, Italy. Sci. Total Environ. 438, 15-25.

Pouet, M.F., Baures, E., Vaillant, S., Thomas, O., 2004. Hidden isosbestic point(s) in UV spectra. Appl. Spectrosc. 58, 486-490.

Quintana, J.B., Rodil, R., López-Mahía, P., MuniateguiLorenzo, S., Prada-Rodríguez, D., 2010. Investigating the chlorination of acidic pharmaceuticals and by-product formation aided by an experimental design methodology. Water Res. 44, 243-255.

Ratola, N., Cincinelli, A., Alves, A., Katsoyiannis, A., 2012. Occurrence of organic microcontaminants in the wastewater treatment process. A mini review. J. Hazard. Mater. 239-240, 1-18.

Roberts, P.H., Thomas, K.V., 2006. The occurrence of selected pharmaceuticals in wastewater effluent and surface waters of the lower Tyne catchment. Sci. Total Environ. 356, 143-153.

Roberts, G., Myatt, G., Johnson, W., Cross, K., Blower, P.J., 2000. LeadScope: software for exploring large sets of screening data. J. Chem. Inf. Comput Sci. 40, 1302-1314.
Rodil, R., Quintana, J.B., Cela, R., 2012. Transformation of phenazone-type drugs during chlorination. Water Res. 46, 2457-2468.

Saiakhov, R., Chakravarti, S., Klopman, G., 2013. Effectiveness of CASE ultra expert system in evaluating adverse effects of drugs. Mol. Inform. 32, 87-97.

Salamoun, J., Smrz, M., Kiss, F., Salamounová, A., 1987. Column liquid chromatography of methotrexate and its metabolites using a post-column photochemical reactor and fluorescence detection. J. Chromatogr. A 419, 213-223.

Shah, A.D., Kim, J.-H., Huang, C.-H., 2006. Reaction kinetics and transformation of carbadox and structurally related compounds with aqueous chlorine. Environ. Sci. Technol. 40, 7228-7235.

Soufan, M., Deborde, M., Legube, B., 2012. Aqueous chlorination of diclofenac: kinetic study and transformation products identification. Water Res. 46, 3377-3386.

Stackelberg, P.E., Furlong, E.T., Meyer, M.T., Zaugg, S.D., Henderson, A.K., Reissman, D.B., 2004. Persistence of pharmaceutical compounds and other organic wastewater contaminants in a conventional drinking-water-treatment plant. Sci. Total Environ. 329, 99-113.

Straub, J.O., 2010. Combined environmental risk assessment for 5-fluorouracil and capecitabine in Europe. Integr. Env. Assess. Manag. 6, 540-566.

Uchiyama, M., Matsumoto, T., Matsumoto, T., Jimi, S., Takamatsu, Y., Tamura, K., Hara, S., 2012. Simple and sensitive HPLC method for the fluorometric determination of methotrexate and its major metabolites in human plasma by post-column photochemical reaction. Biomed. Chromatogr. 26, $76-80$.

Verlicchi, P., Al Aukidy, M., Zambello, E., 2012. Occurrence of pharmaceutical compounds in urban wastewater: removal, mass load and environmental risk after a secondary treatment - a review. Sci. Total Environ. 429, 123-155.

Wang, C., Shi, H., Adams, C.D., Gamagedara, S., Stayton, I., Timmons, T., Ma, Y., 2011a. Investigation of pharmaceuticals in Missouri natural and drinking water using high performance liquid chromatography-tandem mass spectrometry. Water Res. 45, 1818-1828.

Wang, P., He, Y.-L., Huang, C.-H., 2011b. Reactions of tetracycline antibiotics with chlorine dioxide and free chlorine. Water Res. 45, 1838-1846.

Westerhoff, P., Yoon, Y., Snyder, S., Wert, E., 2005. Fate of endocrine-disruptor, pharmaceutical, and personal care product chemicals during simulated drinking water treatment processes. Environ. Sci. Technol. 39, 6649-6663.

Yin, J., Shao, B., Zhang, J., Li, K., 2010. A preliminary study on the occurrence of cytostatic drugs in hospital effluents in Beijing, China. Bull. Environ. Contam. Toxicol. 84, 39-45.

Zounková, R., Odráska, P., Dolezalová, L., Hilscherová, K., Marsálek, B., Bláha, L., 2007. Ecotoxicity and genotoxicity assessment of cytostatic pharmaceuticals. Environ. Toxicol. Chem. 26, 2208-2214. 